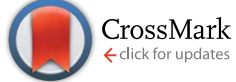

Cite this: RSC Adv., 2016, 6, 5797
Received 26th November 2015 Accepted 22nd December 2015

DOI: $10.1039 / c 5 r a 25172 a$

www.rsc.org/advances

\section{Non-stoichiometric formation of formic and levulinic acids from the hydrolysis of biomass derived hexose carbohydrates $\uparrow$}

\begin{abstract}
T. Flannelly, M. Lopes, L. Kupiainen, S. Dooley and J. J. Leahy*
This study challenges the assumption often postulated in the literature regarding the stoichiometric formation of formic and levulinic acids from the acid hydrolysis of hexose carbohydrates. Acid hydrolysis experiments are conducted with $2.5 \mathrm{wt} \% \mathrm{H}_{2} \mathrm{SO}_{4}$ in aqueous media with a series of reactants relevant to the hydrolysis systems of hexoses; D-fructose, D-galactose, D-glucose, D-mannose, 5-hydroxymethylfurfural, D-erythrose, levulinic acid, furfuryl alcohol, furfural, dihydroxyacetone, glyceraldehyde, pyruvaldehyde and formic acid at $150{ }^{\circ} \mathrm{C}$. We show that the hydrolysis of 5-hydroxymethylfurfural, which is the main intermediate between hexose carbohydrates and levulinic acid does result in the stoichiometric formation of formic and levulinic acids. However, in all cases with hexose carbohydrates as reactant, formic acid is observed in excess fractions to levulinic acid, implying the common assumption is inaccurate. At steady-state conversions of the reactant, the formic and levulinic acid ratio for D-fructose, D-glucose, D-mannose and $\mathrm{D}$-galactose is shown to be $1.08 \pm 0.05,1.15 \pm 0.08,1.20 \pm 0.10$ and $1.19 \pm 0.08$ respectively. Combining this work and pertinent literature suggests there are at least four potential pathways depending on reaction condition responsible for the excess formic acid; through furfuryl alcohol and furfural formation and through the transformation of D-erythrose and pyruvaldehyde.
\end{abstract}

\section{Introduction}

Levulinic acid is a bio-based platform chemical formed by the treatment of hexose carbohydrates from lignocellulosic biomass, and is a precursor for the production of potential future fuels and chemicals. Levulinic acid possesses the versatile ketone and carboxylic acid functional groups, which has led to the US Department of Energy recognising it as one of the top ten most attractive value-added chemicals obtainable from

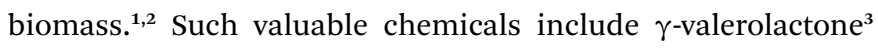
and levulinate esters, ${ }^{4}$ among other appealing chemicals such as angelica lactone, diphenolic acid, and $\delta$-amino levulinic acid. ${ }^{5}$ Acid hydrolysis is presently the prevalent approach for levulinic acid generation from cellulosic materials. Thus there is considerable work being conducted to comprehend the mechanistic details, in order to maximise yields of levulinic acid formation from lignocellulosic derived cellulose and hemicelluloses. ${ }^{6,7}$ Typical processes for levulinic acid formation employ high temperatures $\left(150-200{ }^{\circ} \mathrm{C}\right.$ ), (purportedly) and various acids as catalyst, where yields of up to $70 \mathrm{~mol} \%$ have been achieved with 1-5 wt $\%$ sulphuric acid. ${ }^{8}$

Department of Chemical and Environmental Sciences, University of Limerick, Ireland. E-mail: J.J.Leahy@ul.ie

$\dagger$ Electronic supplementary information (ESI) available: Containing chromatograms for each species detected as well as time resolved profiles of other reactions products. See DOI: 10.1039/c5ra25172a
Less attention is given to the formic acid that is produced as a reaction (by-) product with levulinic acid. Formic acid is a valuable product in its own right and can be used as a commodity in the chemical and textiles industry, as a catalyst, a hydrogen carrier and a road salting component. ${ }^{9}$ In particular, the capability of formic acid as a hydrogen carrier is appealing; therefore attempts to optimize this reaction are being aggressively pursued by employing a variety of homogenous and heterogeneous catalysts. ${ }^{10}$ The original Biofine process ${ }^{11}$ suggested that formic and levulinic acids are formed stoichiometrically from lignocellulosic biomass and the potential formic acid formed as side products is largely ignored (see Fig. 1).

This historical assumption still prevails in the literature with many reports of the stoichiometric formation of formic and levulinic acids from cellulose and cellulosic derived hexoses. ${ }^{12,13}$

Concentration ratios of unity are frequently stated, in some cases it is unclear whether the formic acid concentrations reported are measured, or merely assumed following the historical appraisal. It is worth noting that formic acid can undergo decomposition at high temperatures leading to uncertainties about the exact amount of formic acid formed. This is apparent in the work of Zhang et al. ${ }^{14}$ where the authors state that formic acid degraded to $\mathrm{H}_{2} \mathrm{O}$ and $\mathrm{CO}_{2}$ at $180{ }^{\circ} \mathrm{C}$, leading to levulinic acid concentrations in excess of formic acid concentrations (a sub-unity ratio). Recently there has been other reports of nonequimolar ratios of formic and levulinic acids from the hydrolysis of hexose starting materials at steady-state. For example in 


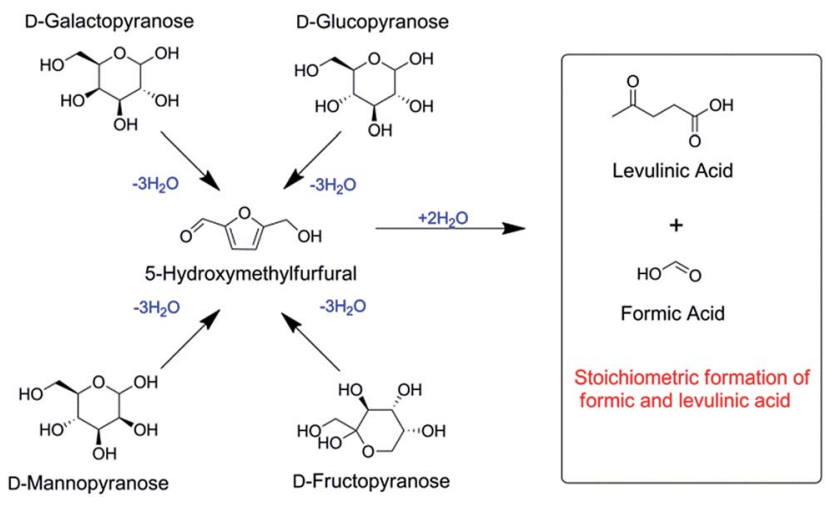

Fig. 1 The historical understanding of the stoichiometric formation of formic and levulinic acids, from cellulosic and hemicellulosic derived hexose carbohydrates.

2013 Swift et al. ${ }^{15}$ claimed to report for the first time of the formation of non-stoichiometric ratios of formic to levulinic acids from the dehydration of $\mathrm{D}$-fructose. Other recent studies have also reported non stoichiometric ratios using D-fructose, Dglucose and cellulose as reactants, with both Qi et al., and Kumar et al., reporting ratios in excess of 1 . Whilst the formation and consumption of formic acid from hexose hydrolysis is poorly understood, it is clear that formic and levulinic acids are formed stoichiometrically from 5-hydroxymethylfurfural as reactant. ${ }^{\mathbf{1 5 , 1 6}}$ This common assumption and apparent confusion may be due to not treating the hydrolysis of hexoses and the subsequent hydrolysis of 5-hydroxymethylfurfural as separate identities. A library of formic-to-levulinic acid ratios reported in the literature from various reactants is summarized in Table 1.

Clearly, formic acid production results from a complicated chemical mechanism. However, information on all of the discrete pathways responsible for the non-equimolarity to levulinic acid is as of yet unclear. Despite this, there is common agreement that the excess in formic acid is likely to be formed

Table 1 Literature overview of formic/levulinic acid ratios reported using 5-hydroxymethylfurfural and hexoses as reactant. Note water is the medium unless stated

\begin{tabular}{|c|c|c|c|c|}
\hline Reactant & $\begin{array}{l}\text { Temperature } \\
\left({ }^{\circ} \mathrm{C}\right)\end{array}$ & Catalyst & $\begin{array}{l}\mathrm{FA} / \mathrm{LA} \\
\text { ratio }\end{array}$ & Reference \\
\hline 5-HMF & 98-181 & $\mathrm{H}_{2} \mathrm{SO}_{4}$ & 1 & Girisuta et al. ${ }^{7}$ \\
\hline 5-HMF & $70-150$ & $\mathrm{H}_{2} \mathrm{O}, \mathrm{HCl}$ & 1 & Swift et al. ${ }^{15}$ \\
\hline D-Fructose & 130 & $\begin{array}{l}\mathrm{H}_{2} \mathrm{SO}_{4} \mathrm{GVL} \\
\text { solvent }\end{array}$ & $>1$ & Qi et $a l^{19}$ \\
\hline D-Fructose & $70-150$ & $\mathrm{HCl}$ & $>1$ & Swift et al. ${ }^{29}$ \\
\hline D-Fructose & 240 & $\mathrm{H}_{3} \mathrm{PO}_{4}$ & $>1$ & Asghari et al. ${ }^{18}$ \\
\hline D-Glucose & 90 & $\mathrm{HCl}$ and $\mathrm{ZnBr}_{2}$ & 1.46 & Kumar et al. ${ }^{25}$ \\
\hline D-Glucose & 180 & $\begin{array}{l}\text { Maleic acid, } \\
\mathrm{AlCl}_{3}\end{array}$ & $<1$ & Zhang et al. ${ }^{14}$ \\
\hline D-Glucose & 140 & $\mathrm{HCl}$ & 1.10 & Yang et $a ._{.}^{22}$ \\
\hline D-Glucose & 170 & Mineral acids & 1.20 & $\begin{array}{l}\text { Rackemann and } \\
\text { Doherty }^{17}\end{array}$ \\
\hline Cellulose & 180 & $\mathrm{ZnO}_{2}$ & $>1$ & Joshi et al. ${ }^{12}$ \\
\hline Cellulose & $160-200$ & $\mathrm{HCl}$ & 1 & $\begin{array}{l}\text { Shen and } \\
\text { Wyman }^{13}\end{array}$ \\
\hline
\end{tabular}

either from direct hexose decomposition or indirectly through hexose consumption of intermediate species during hexose hydrolysis. ${ }^{17,18}$ For example Qi et al., when using an isotopic labelling approach to decipher the D-glucose/D-fructose dehydration pathways for the formation of levulinic acid, observed non isotopically labelled formic acid originating from both $\mathrm{D}^{-}$ glucose and D-fructose. ${ }^{19}$ Asghari and Yoshida hypothesized when observing non-equimolar ratios of formic and levulinic acid that, formic acid and other organic acids were directly produced from the decomposition of $\mathrm{D}$-fructose.$^{\mathbf{1 8}}$ Formic acid has also been reported as a degradation product of well-known hexose decomposition products such as dihydroxyacetone, glyceraldehyde and pyruvaldehyde at high temperatures $\left(>300{ }^{\circ} \mathrm{C}\right)$ in subcritical water..$^{20,21}$ Joshi et al., using a zirconium dioxide catalyst suggested that the excess in formic acid is formed from a D-glucose starting material through the formation of 1,6-D-anhydroglucose which then subsequently undergoes hydrolysis forming furfural, formic acid and hydrogen stoichiometrically. ${ }^{12}$ Moreover, of recent significance is the study conducted by Yang et al., who used computational density functional theory to elaborate a "micro-kinetic" model for the glucose/Bronsted acid aqueous system. They infer that the excess formic acid appears at high temperatures and originates from aldol condensation chemistry involving the carbon "six" atom of D-glucose which results in the direct formation of furfuryl alcohol and in the concurrent release of formic acid. ${ }^{22}$ Another possible source of formic acid is through the intermediate of $\mathrm{D}$-erythrose which has been reported both from $\mathrm{D}^{-}$ fructose $^{23}$ and $\mathrm{D}$-glucose $\mathrm{C}^{24}$ as primary reactants.

Despite all of this information, there is still an apparent lack of clarity on the supposed stoichiometric formation of formic and levulinic acids from acid hydrolysis of hexose carbohydrates. For example Kumar et al., recently stated "theoretically, equimolar amounts of levulinic and formic acids were expected from the conversion of D-glucose through the intermediate 5-hydroxymethylfurfural". ${ }^{25}$ To this effect, Victor et al. commented "In principle the ratio (w/w\%) of levulinic and formic acids in the product hydrolyzate should be 2.5 as only one molecule of formic acid is formed per each glucose molecule that is converted to levulinic acid". ${ }^{26}$

In light of all of the above it is necessary to intentionally challenge the common assumption that formic and levulinic acids are formed stoichiometrically from hexose carbohydrate starting materials with scientific rigour for the first time. To do so we perform experimental characterisation of the mechanism of acid hydrolysis using $2.5 \mathrm{wt} \% \mathrm{H}_{2} \mathrm{SO}_{4}$ in water for a series of reactants relevant to the hydrolysis systems of hexoses extending to; D-fructose, D-galactose, D-glucose, D-mannose, 5-hydroxymethylfurfural, D-erythrose, levulinic acid, furfuryl alcohol, furfural, pyruvaldehyde, dihydroxyacetone, glyceraldehyde and formic acid at $150{ }^{\circ} \mathrm{C}$.

\section{Experimental}

\section{Materials}

D-Fructopyranose (D-fructose) (CAS 57-48-7, 99\% purity), $\alpha / \beta-\mathrm{D}^{-}$ glucopyranose (D-glucose) (CAS 50-99-7, 99\% purity) $\alpha / \beta$-D- 
mannopyranose (D-mannose), (3458-28-4, 99\% purity) D-galactopyranose (D-galactose) (CAS 59-23-4 99\% purity), sulphuric acid $\left(\mathrm{H}_{2} \mathrm{SO}_{4}, 95-97 \%\right.$ purity), glyceraldehyde (CAS 56-82-6 90\% purity), pyruvaldehyde (CAS 78-98-8 40\% purity), lactic acid (CAS 50-21-5 85\% purity), acetic acid (CAS 64-19-7 99\% purity) 5hydroxymethylfurfural (CAS 67-47-0, 99\% purity) furfural (CAS 98-08-1, 98\% purity) furfuryl alcohol (CAS 98-00-0 97.5\% purity) and levulinic acid (CAS 59-23-4 97\% purity) are each obtained from Sigma Aldrich Ireland and used without further purification. Dihydroxyacetone (CAS 96-26-4 97\% purity) and D-erythrose (CAS 533-493) are purchased from Carbosynth UK and used without further purification.

\section{Experimental}

Experiments are carried out with D-fructose, D-galactose, Dglucose, D-mannose as reactants for determining the formic/ levulinic acid ratio. The experiments are executed at the prescribed temperature using $\mathrm{H}_{2} \mathrm{SO}_{4}$ to catalyse the system and samples are taken at fixed intervals of $30 \mathrm{~min}, 1 \mathrm{~h}, 2 \mathrm{~h}, 4 \mathrm{~h}, 6 \mathrm{~h}, 8$ $\mathrm{h}$ and $10 \mathrm{~h}$. A control reaction is conducted with 5-hydroxymethylfurfural for the purposes of the validation of experimental results. Additional experiments are carried out using the same reaction conditions with levulinic acid, furfuryl alcohol, furfural, dihydroxyacetone, glyceraldehyde, pyruvaldehyde, and formic acid for the determination of the origins of nonequimolar amounts of formic acid. A reactant concentration of $0.3 \mathrm{~mol} \mathrm{~L}^{-1}$ is chosen in order to replicate typical acid hydrolysis processes reported in the literature. A test temperature of $150{ }^{\circ} \mathrm{C}$ is selected in order to ensure that no formic acid decomposition occurs once formed. All experiments are carried out in glass pressure tubes $(25.4 \mathrm{~mm}$ O.D. $\times 10.2 \mathrm{~cm})$, comprising of polytetrafluoroethylene plugs and fluoroelastomer with tetrafluoro O-rings for pressure sealing up to 1.03 MPa. A $5.0 \mathrm{~mL}$ aqueous solution containing the desired concentration of reactant and $\mathrm{H}_{2} \mathrm{SO}_{4}(2.5 \mathrm{wt} \%)$ is placed into the tubes. After being sealed, each tube is placed for a defined period of time in an oil bath set at the desired reaction temperature. When the reaction time is completed, each tube is a)

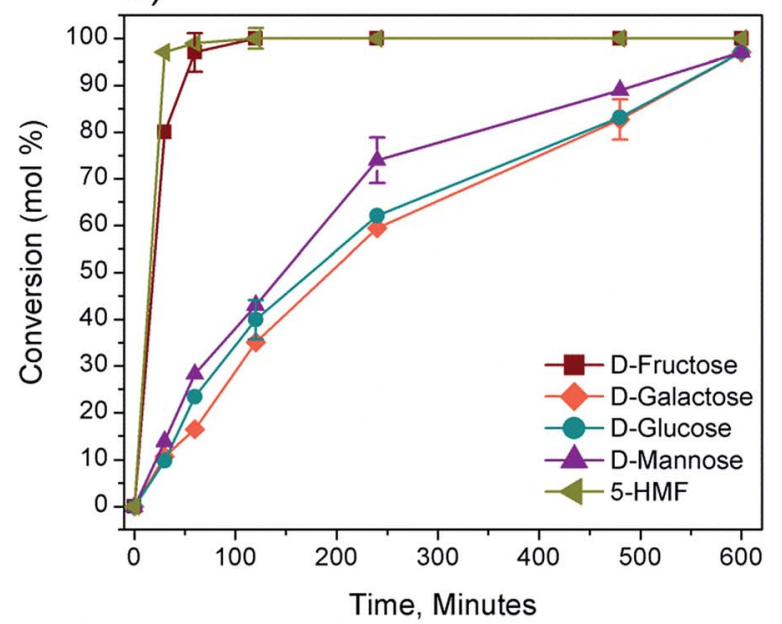

c)

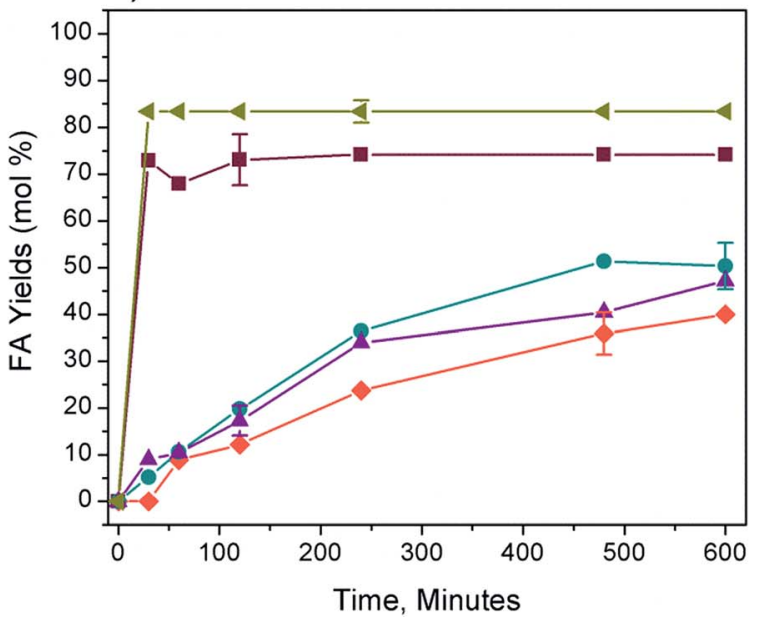

b)

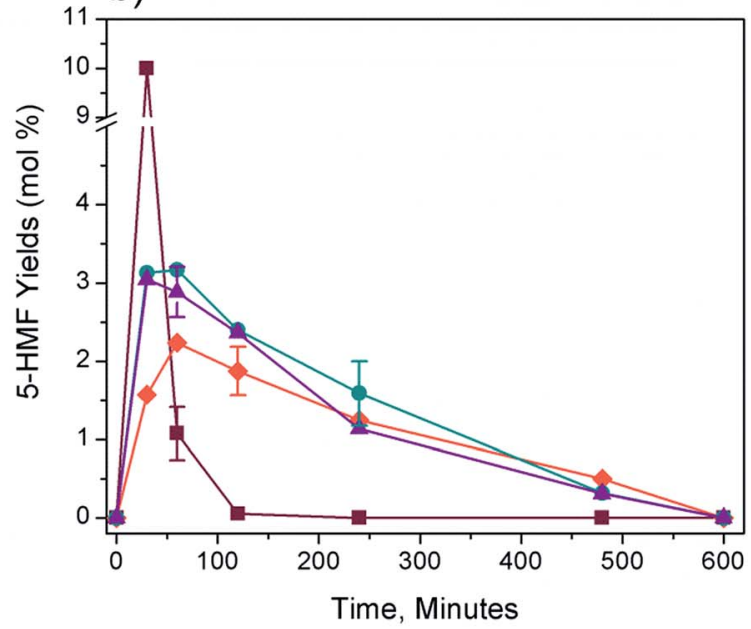

d)

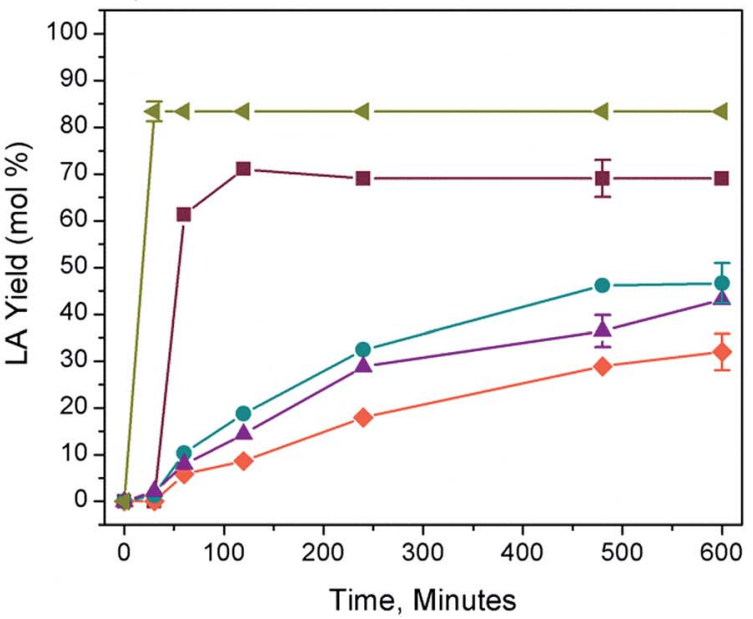

Fig. 2 Experimental data for; (a) reactant conversions, (b) 5-hydroxymethylfurfural (5-HMF) yields, (c) formic acid (FA) yields (d) levulinic acid (LA) yields. All experiments use $2.5 \mathrm{wt} \% \mathrm{H}_{2} \mathrm{SO}_{4}$ in water at $150{ }^{\circ} \mathrm{C}$ with a reactant loading of $0.3 \mathrm{~mol} \mathrm{~L}^{-1}$. 
removed from the oil bath and immersed in a cold water bath to quench the reaction. Samples are then prepared for analysis.

Identification and quantification of D-fructose, D-galactose, D-glucose, D-mannose 5-hydroxymethylfurfural, and dihydroxyacetone is carried with a ion chromatography system (IC) system (Dionex Corp., Sunnydale, CA) equipped with a pulsed amperometric detector (AS, $10 \mu \mathrm{L}$ sample loop, Dionex Corp., Sunnydale, CA). Analysis is performed at $18{ }^{\circ} \mathrm{C}$ by isocratic elution with deionised water $\left(18.2 \mathrm{M} \Omega \mathrm{cm}\right.$ at a flow rate of $1.1 \mathrm{~mL} \mathrm{~min}^{-1}$ ) using a Dionex CarboPac PA1 carbohydrate column. The column is reconditioned using a mixture of $0.4 \mathrm{~mol} \mathrm{~L}^{-1}$ sodium hydroxide and $0.24 \mathrm{~mol} \mathrm{~L}^{-1}$ sodium acetate after each analysis.

For the determination of levulinic acid, furfuryl alcohol, glyceraldehyde, pyruvaldehyde, formic acid, lactic acid and acetic acid, chromatographic separation is achieved using a Dionex Acclaim ${ }^{\circledR}$ organic acid column $(5 \mu \mathrm{m}, 4.6 \times 25 \mathrm{~mm})$ coupled with a guard column cartridge $(5 \mu \mathrm{m}, 4.6 \times 10 \mathrm{~mm})$. Isocratic separation is carried out using $100 \mathrm{mM} \mathrm{Na}_{2} \mathrm{SO}_{4}$ at a $\mathrm{pH}$ of $2.65(0.55 \mathrm{~mL}$ of methanesulfonic acid per every $1 \mathrm{~L}$ of

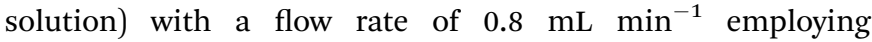
a temperature of $30{ }^{\circ} \mathrm{C}$ for separation. A DAD-3000RS is employed at a wavelength of $210 \mathrm{~nm}$ for the detection of analytes. For both types of analysis described, species are identified by matching retention times to known standards, and quantified by calibration of detector response to known concentrations. Detector responses for compounds of interest and chromatograms for both analytical methods used are available in the ESI (Fig. SI1-SI $4 \dagger$ ).

\section{Calculations and uncertainty analysis}

Molar yields, selectivity and the amount of excess formic acid are calculated by the implementation of the following equations:

$$
\begin{gathered}
\operatorname{Molar} y i e l d(Y)=\frac{C_{(Y), t}-C_{(X), 0}}{C_{(X), 0}} \times 100 \\
\operatorname{Selectivity}(Z)=\frac{C_{(Z), t}-C_{(Z), 0}}{C_{(Z), 0}-C_{(X), t}} \times 100
\end{gathered}
$$

where: $C_{(Y), t}$ is the molar concentration of the product of interest at a time $(t) . C_{(Y), 0}$ is the molar concentration of the product of interest at time zero. $C_{(X), 0}$ is the molar concentration of the reactant at time zero. $C_{(Z), t}$ is the molar concentration of the product of interest at a time $(t) . C_{(Z), 0}$ is the molar concentration of the product of interest at time zero. $C_{(X), t}$ is the molar concentration of the reactant at a time $(t)$.

The term "excess formic acid" is defined by the eqn (3):

$$
\text { Excess formic acid }=\frac{C_{(\mathrm{FA}), \mathrm{T}}-C_{(\mathrm{FA}), 5-\mathrm{HMF}}}{C_{(\mathrm{FA}), 5-\mathrm{HMF}}} \times 100
$$

$C_{(\mathrm{FA}), \mathrm{T}}$ is the total molar concentration of formic acid detected.

$C_{(\mathrm{FA}), 5-\mathrm{HMF}}$ is the molar concentration of formic acid detected from the reaction of 5-hydroxymethylfurfural. This is assumed to be the same is the detected concentrations of levulinic acid.

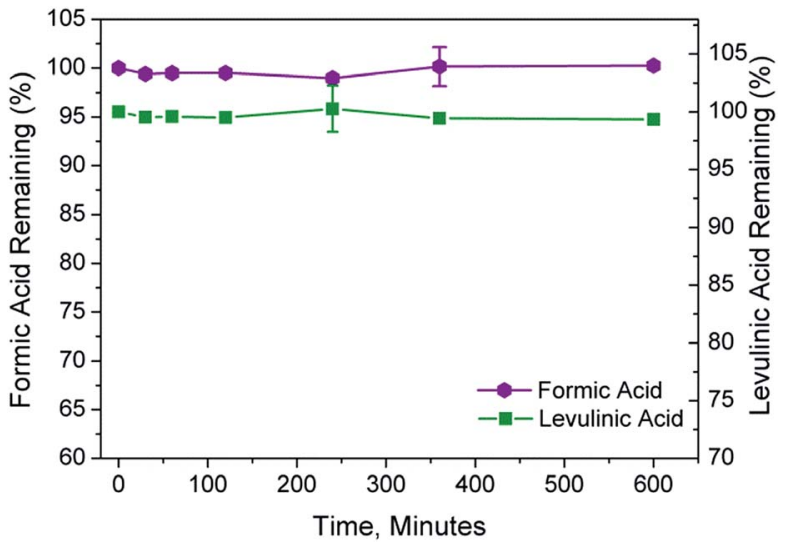

Fig. 3 Stability of formic and levulinic acid in the presence of $2.5 \mathrm{wt} \%$ $\mathrm{H}_{2} \mathrm{SO}_{4}$ at $150{ }^{\circ} \mathrm{C}$. Note the variability of the conversion measurement is within experimental uncertainty.

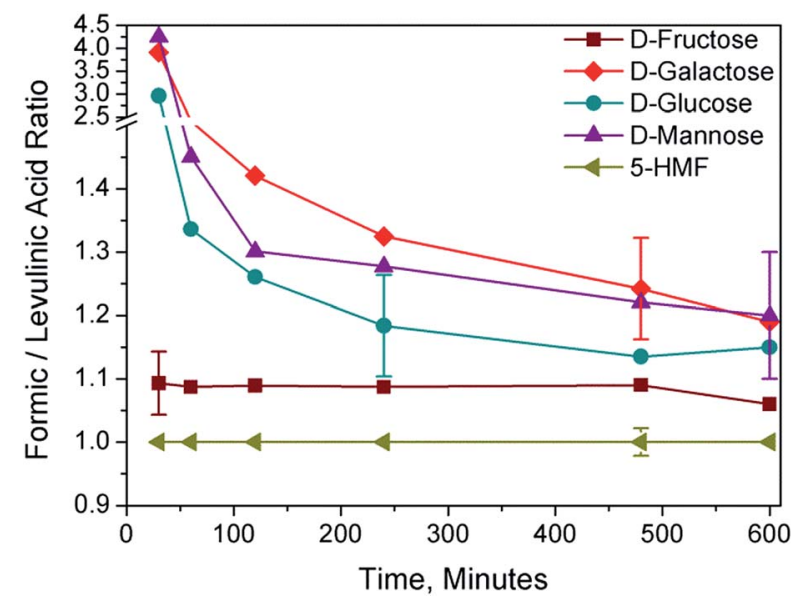

Fig. 4 Formic/levulinic acid ratios per time considering each model compound as reactant.

Where possible all experiments are repeated in duplicate and experimental uncertainties are denoted on all data sets reported, see Fig. 2-4 and Fig. 6.

\section{Results and discussion}

\section{Hexose conversion rates}

The kinetic timescale as well as the mechanistic detail of the dehydration reactions is found to vary with each hexose tested. Fig. 2 illustrates this behaviour in terms of reactant conversion and their tendency to form 5-hydroxymethylfurfural, formic acid and levulinic acid at $150{ }^{\circ} \mathrm{C}$ catalysed by $2.5 \mathrm{wt} \% \mathrm{H}_{2} \mathrm{SO}_{4}$. The rate of primary reactant conversion (Fig. 2(a)) is in the order of 5-hydroxymethylfurfural $>$ D-fructose $>$ D-mannose with similar conversions observed for D-galactose and D-glucose. This is in line with the findings of Baugh and McCarty who found the hexose carbohydrate consumption rate to order as; D-mannose > D-galactose $>$ D-glucose. ${ }^{27}$ 


\section{Levulinic acid yields}

It is evident that both selectivity to 5-hydroxymethylfurfural and yields of levulinic acid from $\mathrm{D}$-fructose $(70 \mathrm{~mol} \%)$ are higher than those from the other hexose carbohydrates. The conversion rates of D-mannose, D-glucose and D-galactose are similar (Fig. 2(a)), but their mechanistic propensity to form 5-hydroxymethylfurfural differs. Selectivity to 5-hydroxymethylfurfural from the model hexoses is in the order of; D-fructose $>$ D-glucose $>$ D-mannose $>$ D-galactose (Fig. 2(b)). Subsequent yields of levulinic acid also follow this order (D-fructose $>$ D-glucose $>$ D-mannose $>$ D-galactose) (Fig. 2(c)). This is consistent with the findings of $\mathrm{Hu}$ et al., who found the yields of levulinic acid from various sugars to be in the order of $\mathrm{D}$-fructose $>$ D-glucose $>$ D-galactose. ${ }^{28}$ As expected levulinic acid yields are significantly higher from 5-hydroxymethylfurfural ( $83 \mathrm{~mol} \%$ ) than from the hexose carbohydrates.

\section{Ratio of formic acid to levulinic acid}

Fig. 3 depicts that formic and levulinic acid are stable under the conditions employed in this study, and thus are appropriate in order to accurately ascertain the formic to levulinic acid ratio.

Control reactions conducted using 5-hydroxymethylfurfural as reactant result in equimolar formic and levulinic acids as was observed by the work of others..$^{15,16}$ In contrast, the ratio of formic to levulinic acids for all model hexose carbohydrates is found to be $>1$ (Fig. 4). Fig. 4 demonstrates that there is a decrease in the formic/levulinic acid ratios observed with respect to time, particularly in relation to $\mathrm{D}$-mannose, $\mathrm{D}$-glucose and D-galactose. This can be attributed to the fact that formic acid is found to form from the aforementioned hexoses at a faster rate than from the hydration of 5-hydroxymethylfurfural, the presumed dominant pathway. Consequently, with time, as 5-hydroxymethylfurfural is formed and consumed, the high formic/levulinic acid ratio observed at early stages of reaction decreases.

When the model reactions have proceeded to steady-state, the formic/levulinic acid ratios for D-fructose, D-glucose, D-mannose and D-galactose are found to be $1.08 \pm 0.05,1.15 \pm$ $0.08,1.20 \pm 0.10$ and $1.19 \pm 0.08$ respectively. The formic/ levulinic acid ratios observed for $\mathrm{D}$-fructose are in line with the values observed by Swift et al. ${ }^{15}$ and Qi et al. ${ }^{19}$ They both observed formic/levulinic acid ratios of just over 1 . The ratios observed for D-glucose are lower than that observed by Kumar et al. ${ }^{25}$ (1.54) however as all values quoted employ different reaction systems (temperatures, catalysts), precise comparisons are not appropriate. To the best of the authors knowledge little information regarding formic/levulinic acid ratios for $\mathrm{D}^{-}$ mannose and D-galactose is available in the literature. However Swift et $a .^{29}$ recently stated that D-mannose undergoes significant losses to formic acid particularly at low temperatures whilst undergoing acid hydrolysis. From experiment D-fructose is found to have the lowest formic/levulinic acid ratio of all the hexose carbohydrates.

A trend cannot be articulated for D-galactose, D-glucose, D-mannose as the reported values are within the uncertainty estimates for each steady-state measurement.
The results of this study coupled with the recent reports from the literature provide compelling evidence that formic and levulinic acids are not formed stoichiometrically from hexose starting materials. This invalidates the common assumption about the equimolar formation of formic and levulinic acids from lignocellulosic derived carbohydrates.

\section{Pathways to formic acid formation}

The excess in formic/levulinic acid ratios observed for each model hexose carbohydrate deems it necessary to investigate formic acid formation from known hexose intermediates in the system not derived from 5-hydroxymethylfurfural. Fig. 5 shows a simple summary of the behaviour of hexose carbohydrates in aqueous acidic media from the literature and also describes the origin of any potential sources of excess formic acid that have been postulated and are worthy of investigation. At this time a complete census of all potential sources of excess formic acid is not pragmatic, particularly for D-mannose and D-galactose which are less well studied than D-fructose and D-glucose. From consulting the literature it appears excess formic acid formation can be categorised into 2 distinctive groups;

1. Excess formic acid from direct hexose transformations.

2. Excess formic acid from hexose derived intermediates.

\section{Excess formic acid from direct hexose transformations}

Furfuryl alcohol. Perhaps the most pertinent reported pathway for excess formic acid has been recently reported by Yang et al., in which they suggested the formation of excess formic acid from the direct dehydration of hexose carbohydrates to furfuryl alcohol, liberating 2 moles of $\mathrm{H}_{2} \mathrm{O}$. They proposed that the formic acid is formed by the aldol condensation that originates from retro-aldol chemistry in aqueous media involving the carbon "six" atom of D-glucose, subsequently liberating furfuryl alcohol. In our tests conducted with D-galactose, D-glucose, D-fructose and D-mannose furfuryl alcohol is not detected as a stable identity. Consequently under the test conditions of our study furfuryl alcohol is found to be very unstable, with almost $100 \%$ conversion after 5 minutes at $150{ }^{\circ} \mathrm{C}$ with $2.5 \mathrm{wt} \% \mathrm{H}_{2} \mathrm{SO}_{4}$ (see Fig. 6(a)). Therefore furfuryl alcohol detection as a stable intermediate is difficult. The excess formic acid arises as the selectivity of furfuryl alcohol hydration to levulinic acid is significantly lower than from 5-hydroxymethylfurfural (see Fig. 6(b)). Subsequently the selectivity of the hydration of furfuryl alcohol to levulinic acid is found to be significantly lower than from 5-hydroxymethylfurfural $(20 \%$ compared to $80 \%$ ), see Fig. 6(b). Taking D-glucose as an example, using the formic/levulinic acid ratio of 1.15 and the levulinic acid yields of $46 \%$ measured in our investigation, the proposal of Yang et al., is exercised. Combining their suggested reaction pathway with the yield data of our study, results in a selectivity of $8.2 \%$ for furfuryl alcohol formation from D-glucose. This assumes that the described furfuryl alcohol pathway is solely responsible for the excess formic acid. This example illustrates how relatively low selectivity of hexose sugars to furfuryl alcohol can have a significant effect on the formic/levulinic acid ratio. 


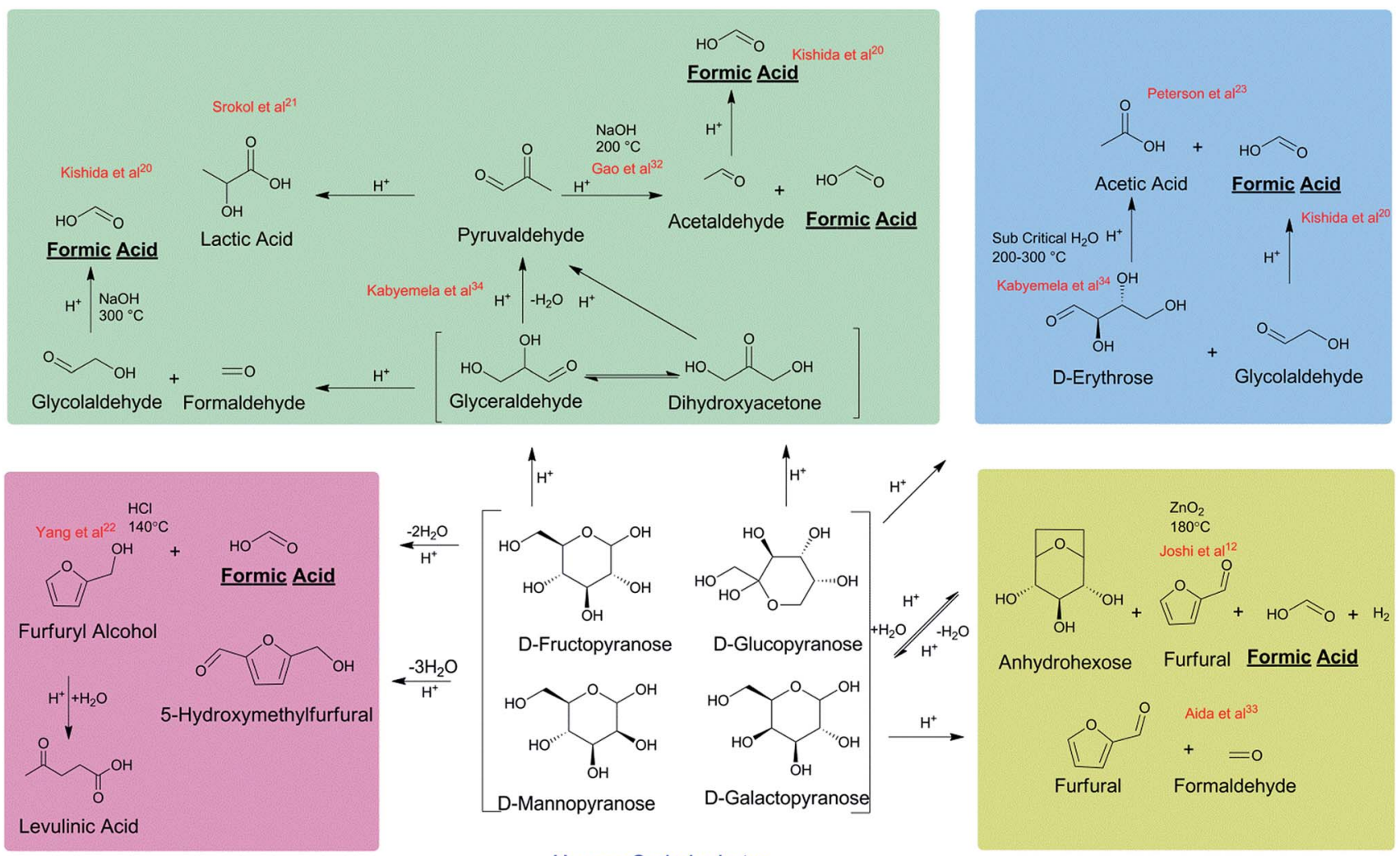

Hexose Carbohydrates

Fig. 5 Possible sources of formic acid that have been reported in the literature.

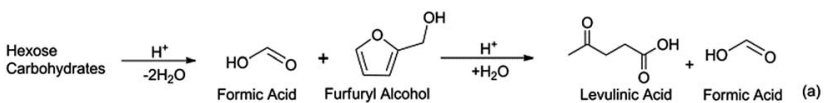

Furfural. The investigation of the formation of furfural as a possible source of formic acid is relevant, as Joshi et al. recently postulated that formic acid can be formed as a byproduct in the formation of furfural though 1,6-anhydro-Dglucose as intermediate liberating equimolar amounts of water, hydrogen and furfural. ${ }^{12}$ Their study was conducted at $180{ }^{\circ} \mathrm{C}$, using cellulose as the primary reactant and zirconium dioxide catalyst and found significant amounts of furfural (up to 10 mol\%).

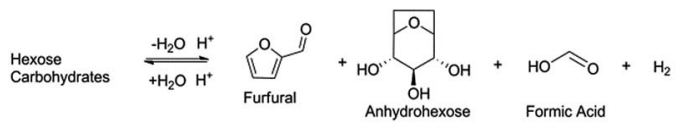

In this study trace amounts of furfural (0.01 mol\%) are detected in the order of D-fructose $>$ D-mannose $>$ D-glucose and D-galactose (see Fig. SI5 $\dagger$ ) as reactant. Control reactions conducted with furfural suggest that it is in a state of flux under the conditions of this study (see Fig. 6(a)). However it is stable enough to be detected if present in significant amounts, thus it is likely not a major contributor to formic acid formation. In any case it is probable that the Lewis acidity exhibited by the zirconium dioxide is responsible for the furfural formation and that this is not a significant process in hexose/mineral acid aqueous systems.
Interestingly, the highest formic/levulinic acid ratio was reported by Kumar et al., (1.54) who also employed a Lewis acid, using metal bromides coupled with $\mathrm{HCl}$ to catalyse the reaction. ${ }^{25}$ It has also been postulated that excess formic acid is derived from the degradation of furfural. ${ }^{30}$ No formic acid is detected from the acid catalysed degradation of furfural in our investigation.

\section{Excess formic acid from hexose derived intermediates}

D-Erythrose and glycolaldehyde. Equimolar D-erythrose and D-glycolaldehyde have both been reported from the decomposition of ${ }^{\mathrm{D}-g l u c o s e} \mathrm{e}^{24}$ and $\mathrm{D}$-fructose. ${ }^{31}$ Peterson et al. ${ }^{23}$ have reported D-erythrose to thermally degrade to form acetic and formic acids between 300 and $350{ }^{\circ} \mathrm{C}$.

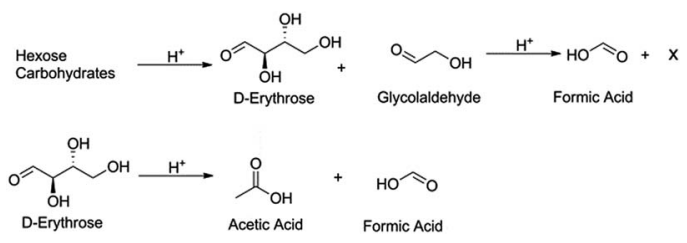

D-Erythrose is detected in our investigation from D-glucose, and D-fructose in trace amounts. No D-erythrose is detected from D-mannose or D-galactose. As Fig. 6(a) depicts D-erythrose is shown to be very reactive under the conditions of this study, and degrades to give formic acid yields of $18 \mathrm{~mol} \%$ at $100 \%$ conversion with acetic acid the other main product detected. 

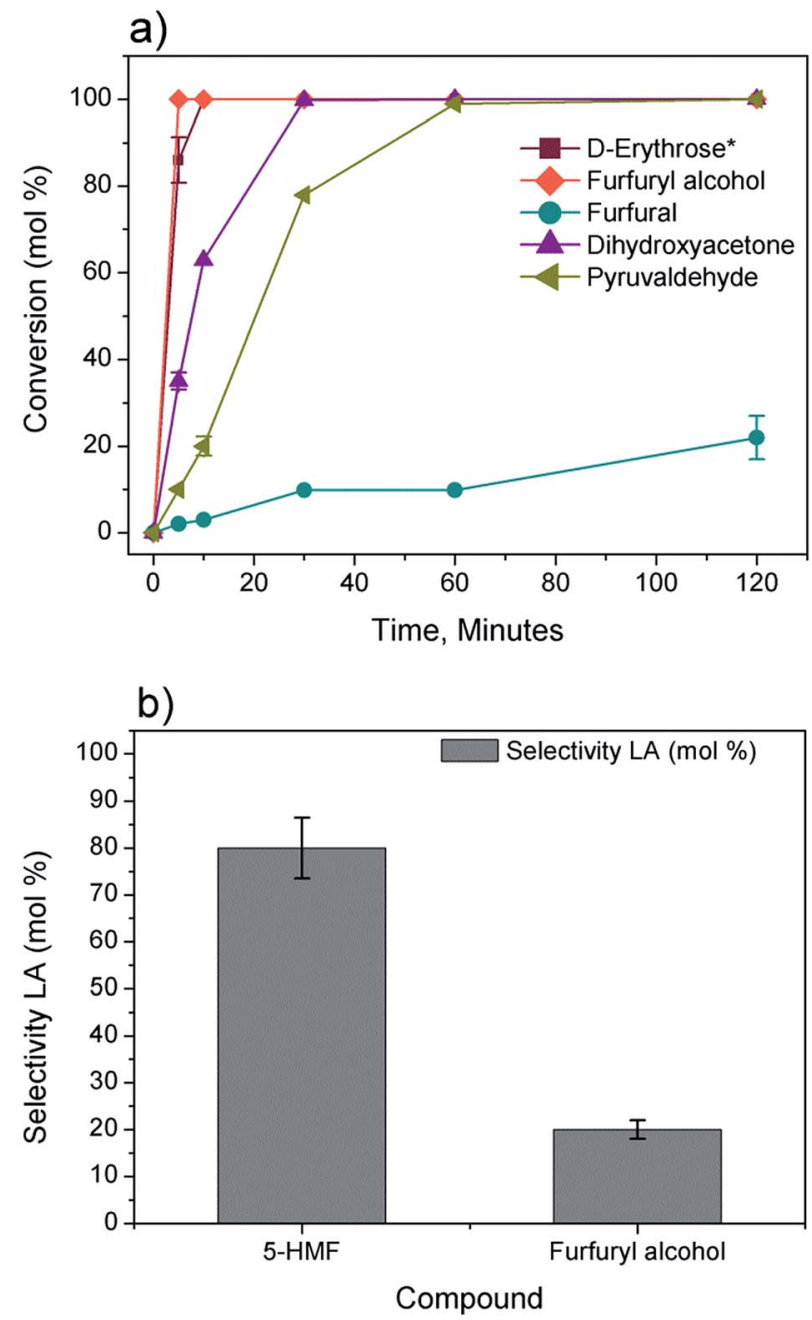

Fig. 6 (a) Stability of model compounds at $150^{\circ} \mathrm{C}$ catalysed by $2.5 \mathrm{wt} \%$ $\mathrm{H}_{2} \mathrm{SO}_{4}$ (b) selectivities of 5-hydroxymethylfurfural and furfuryl alcohol to levulinic acid at $150{ }^{\circ} \mathrm{C}$ catalysed by $2.5 \mathrm{wt} \% \mathrm{H}_{2} \mathrm{SO}_{4}$. "Note only formic acid is detected from $\mathrm{D}$-erythrose.

Therefore it is likely that D-erythrose is a contributor to the excess formic acid formed from D-glucose under conventional hexose acid hydrolysis systems. It is also probable that D-glycolaldehyde, which has been postulated to form stoichiometrically with D-erythrose ${ }^{31}$ can transform to formic acid. For instance Kishida et al., achieved formic acid yields of $13 \mathrm{~mol} \%$ at $300{ }^{\circ} \mathrm{C}$ catalysed by $\mathrm{NaOH} .{ }^{20}$ Potential formic acid formation from D-glycolaldehyde is not investigated in our study due to the difficulty in obtaining it as reactant.

Dihydroxyacetone, glyceraldehyde and pyruvaldehyde. Dihydroxyacetone is the most abundant hexose decomposition product detected in this investigation in the order of $\mathrm{D}$-galactose $>$ D-mannose $>$ D-glucose $>$ D-fructose as reactant and it has been suggested that it's acid catalysed transformations can form formic acid through the pyruvaldehyde intermediate (see Fig. SI5 $\dagger$ ).

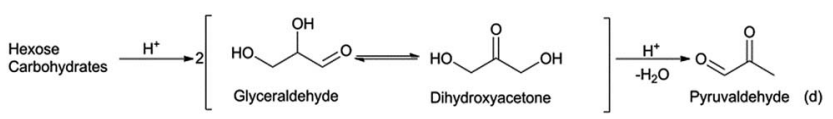

Gao et al., report a competing pathway for the degradation of pyruvaldehyde ${ }^{32}$ forming equimolar formic acid and acetaldehyde at temperatures between 170 and $210{ }^{\circ} \mathrm{C}$ using $\mathrm{NaOH}$ as the catalyst. Kishida et al., ${ }^{20}$ detected formic acid yields of 5.3 mol\% from glyceraldehyde at $300{ }^{\circ} \mathrm{C}$ under alkali conditions.

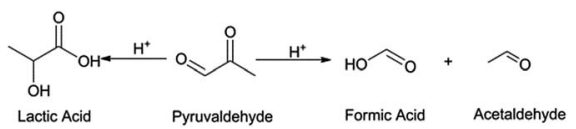

In this study, dihydroxyacetone and glyceraldehyde are found to be reactive (Fig. 6(a)) and are converted quite quickly to pyruvaldehyde which is observed to degrade at a slower rate to lactic and acetic acids. No formic acid is detected for any of the reactions conducted with dihydroxyacetone glyceraldehyde and pyruvaldehyde as reactants. Our investigation suggests, that the formic acid detected by others can be explained by the high temperatures employed and from the use of alkali conditions to catalyse the cellulose/hexose transformations.

Outlook. This investigation highlights that the formation of formic acid from hexose carbohydrates is a complex process with several pathways potentially contributing, in addition to the hydration of 5-hydroxymethylfurfural pathway. Therefore it is clear that formic and levulinic acids are not formed stoichiometrically from hexose carbohydrates, and need to be treated as separate identities when making analysis of formic acid concentrations from the hydrolysis of cellulose and hemicellulosic derived hexose carbohydrates. As Fig. 6(a) illustrates, the potential formic acid forming intermediates are unstable for the test conditions of this study. To ascertain the quantitative contribution of each potential formic acid pathway, dedicated mechanistic experiments and sophisticated kinetic modelling need to be performed on each specific reactant at a range of conditions, representing an avenue for future study.

\section{Conclusion}

The ratio of formic to levulinic acid concentrations for the acid hydrolysis of a series of hexose carbohydrates is found to be $>1$. This deems the commonly held assumption that formic and levulinic acids are formed stoichiometrically from the acid catalysed hydrolysis of hexose carbohydrates to be inaccurate. At steady-state, the formic to levulinic acid ratios for $\mathrm{D}$-fructose, D-glucose, D-mannose and D-galactose are found to be $1.08 \pm$ $0.05,1.15 \pm 0.08,1.20 \pm 0.10$ and $1.19 \pm 0.08$. Analysing this work with pertinent literature suggests there are at least four potential pathways, depending on reaction condition responsible for the formation of the excess formic acid; through; (1) furfuryl alcohol, (2) furfural formation (3) pyruvaldehyde and (4) D-erythrose.

\section{Acknowledgements}

This work is funded by the Irish Research Council as part of the Embark Initiative, by Science Foundation Ireland under the award 13/SIRG/2185, by Science Without Borders and by The Ella and Georg Ehrnrooth Foundation. 


\section{References}

1 T. Werpy, G. Petersen, A. Aden, J. Bozell, J. Holladay, J. White, A. Manheim, D. Eliot, L. Lasure and S. Jones, Top ValueAdded Chemicals from Biomass: Results of Screening for Potential Candidates from Sugars and Synthesis Gas, U.S. Department of Energy, Oak Ridge, TN, 2004, vol. I.

2 J. J. Bozell and G. R. Petersen, Green Chem., 2010, 12, 539554.

3 D. J. Braden, C. A. Henao, J. Heltzel, C. C. Maravelias and J. A. Dumesic, Green Chem., 2011, 13, 1755-1765.

4 G. Pasquale, P. Vázquez, G. Romanelli and G. Baronetti, Catal. Commun., 2012, 18, 115-120.

5 J. J. Bozell, L. Moens, D. Elliott, Y. Wang, G. Neuenscwander, S. Fitzpatrick, R. Bilski and J. Jarnefeld, Resour., Conserv. Recycl., 2000, 28, 227-239.

6 K. Dussan, B. Girisuta, D. Haverty, J. Leahy and M. Hayes, Bioresour. Technol., 2013, 149, 216-224.

7 B. Girisuta, K. Dussan, D. Haverty, J. Leahy and M. Hayes, Chem. Eng. J., 2013, 217, 61-70.

8 D. W. Rackemann and W. O. Doherty, Biofuels, Bioprod. Biorefin., 2011, 5, 198-214.

9 A. Mukherjee, M.-J. Dumont and V. Raghavan, Biomass Bioenergy, 2015, 72, 143-183.

10 M. Zacharska, O. Y. Podyacheva, L. S. Kibis, A. I. Boronin, B. V. Senkovskiy, E. Y. Gerasimov, O. P. Taran, A. B. Ayusheev, V. N. Parmon, J. Leahy and others, ChemCatChem, 2015, 7, 2910-2917.

11 S. W. Fitzpatrick. Lignocellulose degradation to furfural and levulinic acid. U.S. 4, 1990, vol. 897, p. 497.

12 S. S. Joshi, A. D. Zodge, K. V. Pandare and B. D. Kulkarni, Ind. Eng. Chem. Res., 2014, 53, 18796-18805.

13 J. Shen and C. E. Wyman, AIChE J., 2012, 58, 236-246.

14 X. Zhang, B. B. Hewetson and N. S. Mosier, Energy Fuels, 2015, 29(4), 2387-2393, DOI: 10.1021/ef502461s.

15 T. D. Swift, C. Bagia, V. Choudhary, G. Peklaris, V. Nikolakis and D. G. Vlachos, ACS Catal., 2013, 4, 259-267.

16 B. Girisuta, L. Janssen and H. Heeres, Green Chem., 2006, 8, 701-709.

17 D. W. Rackemann and W. O. Doherty, in 34th Australian Society of Sugar Cane Technologists Conference, 2012.
18 F. Salak Asghari and H. Yoshida, Ind. Eng. Chem. Res., 2006, 45, 2163-2173.

19 L. Qi, Y. F. Mui, S. W. Lo, M. Y. Lui, G. R. Akien and I. T. Horváth, ACS Catal., 2014, 4, 1470-1477.

20 H. Kishida, F. Jin, X. Yan, T. Moriya and H. Enomoto, Carbohydr. Res., 2006, 341, 2619-2623.

21 Z. Srokol, A.-G. Bouche, A. van Estrik, R. C. Strik, T. Maschmeyer and J. A. Peters, Carbohydr. Res., 2004, 339, 1717-1726.

22 L. Yang, G. Tsilomelekis, S. Caratzoulas and D. G. Vlachos, ChemSusChem, 2015, 8, 1334-1341, DOI: 10.1002/ cssc. 201403264.

23 A. A. Peterson, F. Vogel, R. P. Lachance, M. FrÖling, M. J. Antal Jr and J. W. Tester, Energy Environ. Sci., 2008, 1, 32-65.

24 Y. Matsumura, S. Yanachi and T. Yoshida, Ind. Eng. Chem. Res., 2006, 45, 1875-1879.

25 V. B. Kumar, I. N. Pulidindi and A. Gedanken, RSC Adv., 2015, 5, 11043-11048.

26 A. Victor, I. N. Pulidindi and A. Gedanken, $R S C A d v ., 2014$, 4, 44706-44711.

27 K. D. Baugh and P. L. McCarty, Biotechnol. Bioeng., 1988, 31, 50-61.

28 X. Hu, L. Wu, Y. Wang, Y. Song, D. Mourant, R. Gunawan, M. Gholizadeh and C.-Z. Li, Bioresour. Technol., 2013, 133, 469-474.

29 T. D. Swift, H. Nguyen, A. Anderko, V. Nikolakis and D. G. Vlachos, Green Chem., 2015, 17, 4725-4735.

30 J. R. Mielenz, K. T. Klasson, W. S. Adney and J. D. McMillan, Biotechnology for Fuels and Chemicals: The Twenty-Eighth Symposium, Springer Science \& Business Media, 2009.

31 M. MÖller, F. Harnisch and U. SchrÖder, Biomass Bioenergy, 2012, 39, 389-398.

32 P. Gao, G. Li, F. Yang, X.-N. Lv, H. Fan, L. Meng and X.-Q. Yu, Ind. Crops Prod., 2013, 48, 61-67.

33 T. M. Aida, K. Tajima, M. Watanabe, Y. Saito, K. Kuroda, T. Nonaka, H. Hattori, R. L. Smith and K. Arai, J. Supercrit. Fluids, 2007, 42, 110-119.

34 B. M. Kabyemela, T. Adschiri, R. M. Malaluan and K. Arai, Ind. Eng. Chem. Res., 1999, 38, 2888-2895. 